\title{
Effect of Acupressure versus Aerobic Exercise on Depression in Postmenopausal Women
}

\author{
HALA M. EMARA, Ph.D.*; WAFAA M. KAMAL, Ph.D.*; HOSSAM E.D. HUSSEIN, M.D.** and \\ NERMEEN S. ABD ELAZEIM, M.Sc.* \\ The Department of Physical Therapy for Woman's Health, Faculty of Physical Therapy, Cairo University*, \\ The Department of Gynecology and Obstetrics, Faculty of Medicine, Al-Azhar University**
}

\begin{abstract}
Background: The effect of acupressure and aerobic exercise on depression was a hot topic in physical therapy in the past decades. The results of the research available to date showed that acupressure and exercise training might be a promising, additional, safe and economical method to help in improving depression.
\end{abstract}

Aim of Study: This study was conducted to compare the effect of acupressure versus aerobic exercise on depression in postmenopausal women.

Material and Methods: A sample of 40 postmenopausal women diagnosed with depression by gynecologist and confirmed by Zung self-rating depression scale, their ages ranged from 45 to 55 years with body mass index not exceeded $30 \mathrm{~kg} / \mathrm{m}^{2}$ participated in this study from the outpatient clinic of Kasr Al-Ainy University Hospital, Cairo University. They were distributed into two groups; each consisted of 20 postmenopausal women, Group (A) received acupressure by wearing wrist band for four weeks for 24 hours and Group (B) performing aerobic exercises on treadmill 3 sessions per week for four weeks for a duration 40mins (10mins warming up, 20mins running and 10mins cooling down).

Results: Showed that there was a statistically significant decrease in the value of Zung self-rating depression scale measured at post-treatment compared with the pre-treatment in both study Groups (A) and (B) $(p=0.001)$.

On the other hand at post-treatment, there was a statistical significant decrease in value of Zung self-rating depression scale in Group B $(38.80 \pm 3.02)$ when compared with its corresponding value in Group A $(46.90 \pm 3.82)$ with $\mathrm{Z}$-value $=$ -4.903 and $p$-value $=0.001$.

Conclusion: Both acupressure and aerobic exercise have significant effect on depression in postmenopausal women but, patients may get additional benefit in improving the depression level through aerobic training program more than the acupressure.

Correspondence to: Dr. Hala M. Emara, The Department of Physical Therapy for Woman's Health, Faculty of Physical Therapy, Cairo University, Egypt
Key Words: Aerobic exercise - Acupressure versus - Depression in postmenopausal women.

\section{Introduction}

DEPRESSION is a common psychological condition and estimated to affect 350 million worldwide population [1], which is twice more common in women compared to men. This high risk in women may be caused by hormonal changes in condition such as puberty, pregnancy, and menopausal transition [2], depression is associated with with various morbidities including osteoporosis [3] and cardiovascular disease [4]. Furthermore, hormonal changes are thought to be major contributors to premenstrual dysphoric disorder, as well as mood changes experienced in the postpartum period and at the menopausal transition. Furthermore, estrogen affects both serotonin and norepinephrine, the 2 neurotransmitters thought to be most directly associated with depression [5]

To our knowledge, there was no study in the literature that compared the effect of acupressure verus aerobic exercise on depression in postmenopausal women. So, this study was the first study to compare between the effects of acupressure and aerobic exercise on depression in postmenopausal women.

\section{Material and Methods}

\section{Design:}

The study was a randomized clinical trial.

\section{Recruitment:}

Fourty postmenopausal women diagnosed by gynecologist/psychologist and confirmed by Zung self-rating depression scale recruited from Kasr 
Al-Ainy University Hospital, Cairo, Egypt by announcements to participate in this study extended from July 2018 to December 2018. Informed consent was obtained from each postmenopausal woman after explaining the nature, purpose and benefits of the study. This study was approved by the Research Ethical Committee of the Faculty of Physical Therapy, Cairo University.

\section{Inclusion and exclusion criteria:}

Forty post-menopausal women diagnosed with depression, their age ranged from 45-55 years, their body mass index was less than $30 \mathrm{~kg} / \mathrm{m}^{2}$, also their score in Zung scale questionnaire was ranged from 50-69, they were postmenopausal for at least one year ago, they were not take any hormonal treatment or any medications that may affect the neuromuscular or psychological statues at least 6 months prior to entry in this study or during the study course (4 weeks). Women with medical problems or mental disorders leading to anxiety or history of any current systematic or chronic disease like diabetes, cardiovascular, or thyroid diseases and any woman having psychological trauma as family problems were excluded from this study.

\section{Instrumentations:}

\section{Assessment instrumentations:}

1-Data recording sheet: This was used to record data of each female including; personal history, past history and menstrual history.

2- Weight-height scale: Weight-height scale was used to measure the weight and height for each woman before starting the treatment to calculate the BMI by dividing weight by height squared $\left(\mathrm{Kg} / \mathrm{m}^{2}\right)$.

3- Zung self-rating depression scale: This scale was used to evaluate depression grades of post menopausal women in both groups (A \& B) before and after the end of the study. The Zung self-rating depression scale was designed by Duke University Psychiatrist Dr. William Zung to assess the level of depression for patients diagnosed with depressive disorder [6].

\section{Treatment instrumentations:}

1- Wrist band: Acupressure applied by using wrist band for Group (A), this band having a protruding round plastic button to apply pressure on pericardium 6 (PC6) that worn for four weeks for 24 hours.

2- Treadmill: Treadmill model johnson (Taiwan t700 pro) was used. An incremental protocol on a treadmill was used to apply treatment as a type of aerobic exercise which increased gradually in speed to help participants with low baseline level of physical activity and who were unfamiliar with treadmill walking to accomodate.

\section{Procedures:}

\section{Assessment procedures:}

1-History taking: Data recording sheet was given to each female at the starting of this study. Each female was left for enough time to answer all the questions without interfering with her answers.

2- Weight and height measurements: Weight and height were recorded for each female to calculate $\mathrm{BMI}$ according to the following equation:

$$
\mathrm{BMI}=\frac{\text { Weight }}{\text { Height squared }\left(\mathrm{kg} / \mathrm{m}^{2}\right)}
$$

3- Zung self rating depression scale: Depression was measured using Zung self-rating depression scale before starting treatment and after the end of treatment duration (4 weeks) to evaluate affective, psychological and somatic symptoms that associated with depression, there are 20 items.

There are ten positively worded and ten negatively worded questions. Each question is scored on a scale of 1 through 4 for the ten negatively worded questions and reversed for the positive worded questions that scored on scale of 4 through 1 and (based on these replies: "A little of the time", "some of the time", "good part of the time", "most of the time, scores on the test range from 20 through 80 .

The scores fall into four ranges (20-44) normal range, (45-59) mildly depressed, (60-69) moderately depressed, 70 and above severely depressed.

\section{Scoring:}

Items are structured in terms of positive and negative statements. Responses are scored 1, 2, 3 or 4 according to the severity of the symptom (the negative). Items marked with an (*) (the positive items) are reverse scored (i.e., 4, 3, 2, 1). The items are totaled to give an overall score.

$$
\text { Index }=\frac{\text { Raw score total X } 100}{\text { Maximum score of } 80}
$$

\section{Treatment procedures:}

- Wrist band (acupressure): Acupressure applied by using wrist band for Group (A) that worm for 4 weeks for 24 hours, PC6 is located three finger breadth ( 2 cunes) below the wrist on the inner 
forearm in between the two tendons (palmaris longus and flexor carpi radialis).

The patient sit on comfortable plinth or chair then she was teached how to wear the wrist band by her self by explaining and showing her the neikuan point where is located on her wrists, directly below the space between your index and middle finger. To find it, place the first three fingers of your opposite hand on your wrist and press the spot between your first two tendons, the button should be placed facing down on this point, the patient didn't know this band actually do due to psychological issues and to obtain accurate data, the PC6 point was marked by a marker for her to avoid miss placing the band.

- Treadmill (aerobic exercise): Group (B) performing aerobic exercise on treadmill for four weeks 3 sessions per week, each session was 40mins walking, divided in to $10 \mathrm{mins}$ warming up the woman walk at comfortable pace at zero incline as the speed increase every one or two mins for 10 mins to loosen up the muscles and prepare the body for what's about to come and to avoid injury, 20 mins running then cooling down for $10 \mathrm{mins}$ by decreasing the speed gradually every one or two mins to bring the heart rate back down so that the breathing recovers to a normal rate.

\section{Results}

Test of normality, was used to measure the distribution of data measured pre-treatment. Accordingly, comparison between normally distributed variables in the two groups was performed using unpaired $t$-test.

I- Physical characteristics for both groups ( $A \& \&$ $B)$ : The demographic characteristics of both Groups (A \& B) at baseline (age and BMI) revealed no significant differences between the two groups before treatment (Table 1).

Table (1): Demographic data for both Groups (A \& B).

\begin{tabular}{|c|c|c|c|c|c|c|}
\hline \multirow{2}{*}{ Variables } & \multirow{2}{*}{ Groups } & \multirow{2}{*}{ Mean } & \multirow{2}{*}{ SD } & \multicolumn{2}{|c|}{ Comparison } & \multirow{2}{*}{ S } \\
\hline & & & & $t$-value & $b$-value & \\
\hline \multirow[t]{2}{*}{ Age (yrs) } & Group (A) & 49.90 & \pm 2.08 & -0.473 & 0.639 & NS \\
\hline & Group (B) & 50.20 & \pm 1.94 & & & \\
\hline \multirow{2}{*}{ BMI $\left(\mathrm{kg} / \mathrm{m}^{2}\right)$} & Group (A) & 24.97 & \pm 1.86 & -0.792 & 0.433 & NS \\
\hline & Group (B) & 25.41 & \pm 1.64 & & & \\
\hline
\end{tabular}

\footnotetext{
*SD : Standard Deviation.

$p$ : Probability.

$S$ : Significance.

NS : Non-Significant.
}

\section{II- Zung self rating depression scale:}

Table (2): Intra and inter-group comparison between values of Zung self-rating depression scale in the two studied groups measured pre-and post-treatment.

\begin{tabular}{lllll}
\hline & $\begin{array}{c}\text { Group A } \\
(\mathrm{n}=20)\end{array}$ & $\begin{array}{c}\text { Group B } \\
(\mathrm{n}=20)\end{array}$ & $\begin{array}{c}\mathrm{Z}^{\#} \\
\text { value }\end{array}$ & $\begin{array}{c}p \text { - } \\
\text { value }\end{array}$ \\
\hline Pre-treatment & $56.70 \pm 4.96$ & $57.10 \pm 3.78$ & -0.217 & $0.828(\mathrm{NS})$ \\
Post-treatment & $46.90 \pm 3.82$ & $38.80 \pm 3.02$ & -4.903 & $0.001(\mathrm{~S})$ \\
Mean difference & 9.80 & 18.30 & & \\
$\%$ change & $17.28 \downarrow \downarrow$ & $32.05 \downarrow \downarrow$ & & \\
Z\#\# value & -3.729 & -3.923 & & \\
$p$-value & $0.001(\mathrm{~S})$ & $0.001(\mathrm{~S})$ & & \\
\hline
\end{tabular}

Data are expressed as mean \pm SD.

NS: $p>0.05$ : Not Significant.

Z\# : Mann Whitney test.

$\mathrm{S}: p<0.05$ : Significant.

Z\#\#: Wilcoxon Sign Ranks test.

In Group A, there was a statistical significant decrease in the value of Zung self-rating depression scale measured at post-treatment $(46.90 \pm 3.82)$ when compared with its corresponding value measured at pre-treatment $(56.70 \pm 4.96)$ with $\mathrm{Z}$-value $=$ 3.729 and $p$-value $=0.001$.

Also in Group B, there was a statistical significant decrease in the value of zung self-rating depression scale measured at post-treatment $(38.80$ $\pm 3.02)$ when compared with its corresponding value measured at pre-treatment $(57.10 \pm 3.78)$ with $\mathrm{Z}$-value $=-3.923$ and $p$-value $=0.001$, the percent decrease in the mean value of Zung self-rating depression scale in both Groups A and B were $17.28 \%$ and $32.05 \%$, respectively, on the other hand at post-treatment, there was a statistical significant decrease in value of Zung self-rating

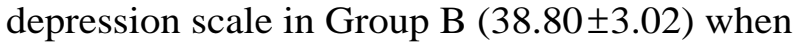
compared with its corresponding value in Group A (46.90 \pm 3.82$)$ with $\mathrm{Z}$-value $=-4.903$ and $p$-value $=0.001$.

\section{Discussion}

Psychological problems and particularly depression is one of problems menopausal women face in the modern societies. It is one of the most common psychiatric disorders, which is not limited to specific time, place, or person and includes all groups and classes of society [7].

Therefore, the current study was conducted to compare the effect of acupressure versus aerobic exercise on depression in postmenopausal women.

\section{The results of this study revealed that:}

The findings of the current study revealed a statistically significant improvement in the mean values of depression level in both groups. These results can be explained that exercise may stabilize the thermoregulatory center and decrease the risk 
of hot flushes, also exercise improve mental health outcomes by providing a distraction or decrease anxiety and enhance psychological feeling. In addition, there is evidence that as increase level of endorphins, the frequency and amplitude of LH hormone decreases, which regulate gonadotropin releasing hormone level levels [8]. Furthermore, aerobic training has the potential to increase serotonin in the brain [9]. Serotonin is an important neurotransmitter for emotional correction [10]

The findings of the current study are in agreement with Zarshenas et al., [11]. Who concluded that four-weeks aerobic exercise can effectively reduce depression symptoms and improve some aspects of body-image attitudes in women. Shortterm aerobic exercise can be used as an effective method of treatment for these disorders. Also Gutierrez et al., [12] supported the findings of this study who stated that a controlled program of physical exercise for postmenopausal women alleviates symptoms of anxiety and depression, and its inclusion in primary healthcare programs should be considered.

It should be noted that some studies do not support the results of the present study regarding reduced depression symptoms with exercise training. Chalder et al., [13] in a randomized controlled trial concluded that the addition of a facilitated physical activity intervention to usual care does not improve depression outcome or reduce use of antidepressants compared with usual care alone. However, treatment of depression with physical activity is designed to improve long-term adherence to physical activity, evidence of a long-term beneficial effect of exercise in patients with clinical depression is limited [14].

Despite the intergroup superior effect of aerobic exercises, the acupressure group also exhibited significant intragroup improvements. These improvements are attributable to acupressure stimulate and release 3 -endorphins and other neurotransmitters such as serotonin and norepinephrine.

Results agreed with Armand et al., [15], who concluded that 4 weeks of acupressure suggested as one of the complementary medicine methods to improve the complications of postmenopausal symptoms.

Rizk and Sahar [16] revealed that all menopausal symptoms was significantly improved among the study than control group after two and three acupressure sessions, in which the duration of this study three successive weeks.
Sun [17] confirmed that the acupoints of Taichong (LR3), Sanyinjiao (SP6), Neiguan (PC6), or Shenmen (HT7), for 6 weeks effective for depression as a recommended dose of fluoxetine.

Moosavi et al., [18] rejected the effect of acupressure in P6 point on anxiety. The findings of this study are not consistent with those of other studies. The reason behind the inconsistency of this study with the other studies conducted is possibly the short time of acupressure in Musavi's study (one minute).

\section{Conclusion:}

Both acupressure and aerobic exercise have significant effect on depression in postmenopausal women but, patients may get additional benefit in improving the depression level through aerobic training program more than the acupressure.

\section{Conflicts of interests:}

All authors disclose no financial or personal relationships with other people or organization that could influence the research's results.

\section{Acknowledgements:}

Many thanks, to all females who participated in this study for their cooperation.

\section{References}

1- MUHARAM R., SETIAWAN M.W., IKHSAN M., RIZKINYA H.E. and SUMAPRAJA K.: Depression and its link to other symptoms in menopausal transition. Middle East Fertility Society Journal, 23 (1): 27-30, 2018.

2- D. BUCHTEMANN, M. LUPPA, A. BRAMESFELD and S. RIEDEL-HELLER: Incidence of late-life depression: A systematic review J. Affect. Disord., 142 (1-3), pp. 172-9, 2012.

3- WEBER M.T., MAKI P.M., McDERMOTT M.P.L.: Cognition and mood in perimenopause: A systematic review and meta-analysis. J. Steroid Biochem. Mol. Biol., 142: 90-8, 2014.

4- WASSERTHEIL-SMOLLER S., SHUMAKER S., OCKENE J., et al.: Depression and cardiovascular sequelae in postmenopausal women. The Women's Health Initiative (WHI) Arch. Intern. Med., 164 (3): 289-98, 2004.

5- HUTTNER R.P. and SHEPHERD J.E.: Gonadal steroids, selective serotonin reuptake inhibitors, and mood disorders in women. Med. Clin. North Am., 87: 1065-76, 2003.

6- ZUNG W.W.: A self-rating depression scale. Archives of General Psychiatry, 12 (1): 63-70, 1965.

7- BROMBERGER J.T., HARLOW S., AVIS N., KRAVITZ H.M. and CORDAL A.: Racial/ethnic differences in the prevalence of depressive symptoms among middle-aged women: The Study of Women's Health Across the Nation (SWAN). American Journal of Public Health, 94 (8): 1378-85, 2004. 
8- DALEY A.J., STOKES-LAMPARD H., THOMAS A., REES M., COLEMAN S., ROALFE A. and MacARTHUR C.: Aerobic exercise as a treatment for vasomotor menopausal symptoms: Randomised controlled trial protocol. Maturitas, 76 (4): 350-6, 2013.

9- PATRICK R.P. and AMES B.N.: Vitamin D and the omega-3 fatty acids control serotonin synthesis and action, part 2: Relevance for ADHD, bipolar disorder, schizophrenia, and impulsive behavior. The FASEB Journal, 29 (6): 2207-22, 2015.

10-HARMER C.J.: Serotonin and emotional processing: Does it help explain antidepressant drug action? Neuropharmacology, 55 (6): 1023-8, 2008.

11-ZARSHENAS S., HOUSHVAR P. and TAHMASEBI A.: The effect of short-term aerobic exercise on depression and body image in Iranian women. Depression research and treatment, 132684, 2013.

12- GUTIÉRREZ C., LUQUE G., MEDINA G. and CASTILLO M.: Influence of exercise on mood in postmenopausal women. Journal of Clinical Nursing, 21 (7-8): 923-8, 2012.

13- CHALDER M., WILES N.J., CAMPBELL J., HOLLINGHURST S.P., HAASE A.M., TAYLOR A.H. and WINDER R.: Facilitated physical activity as a treatment for depressed adults: Randomised controlled trial. BMJ, 344: e2758, 2012.

14- KROGH J., NORDENTOFT M., STERNE J.A. and LAWLOR D.A.: The effect of exercise in clinically depressed adults: Systematic review and meta-analysis of randomized controlled trials. Journal of Clinical Psychiatry, 72 (4): 529-38, 2011

15- ARMAND M., OZGOLI G., GITI R.H. and MAJD H.A.: Effect of acupressure on early complications of menopause in women referring to selected health care centers. Iranian journal of Nursing and Midwifery Research, 22 (3): 237, 2017.

16-RIZK S.A.: Effect of acupressure on menopausal symptoms among women. J. American Sci., 9: 416-24, 2013.

17- SUN H., ZHAO H., MA C., BAO F., ZHANG J., WANG D.H. and HE W.: Effects of electroacupuncture on depression and the production of glial cell line-derived neurotrophic factor compared with fluoxetine: A randomized controlled pilot study. The Journal of Alternative and Complementary Medicine, 19 (9): 733-9, 2013.

18- MOOSAVI S., MIRZAEI M. and REZA S.P.: The effects of acupressure on anxiety nursing, midwifery and operating room students. Journal of Guilan University of Medical Sciences, 18 (71): 82-9, 2009.

\section{تآثير العلاج بالضغط الوخزى مقابل العلاج بالتمرينات الهوائية على الهئ

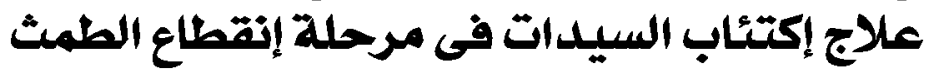

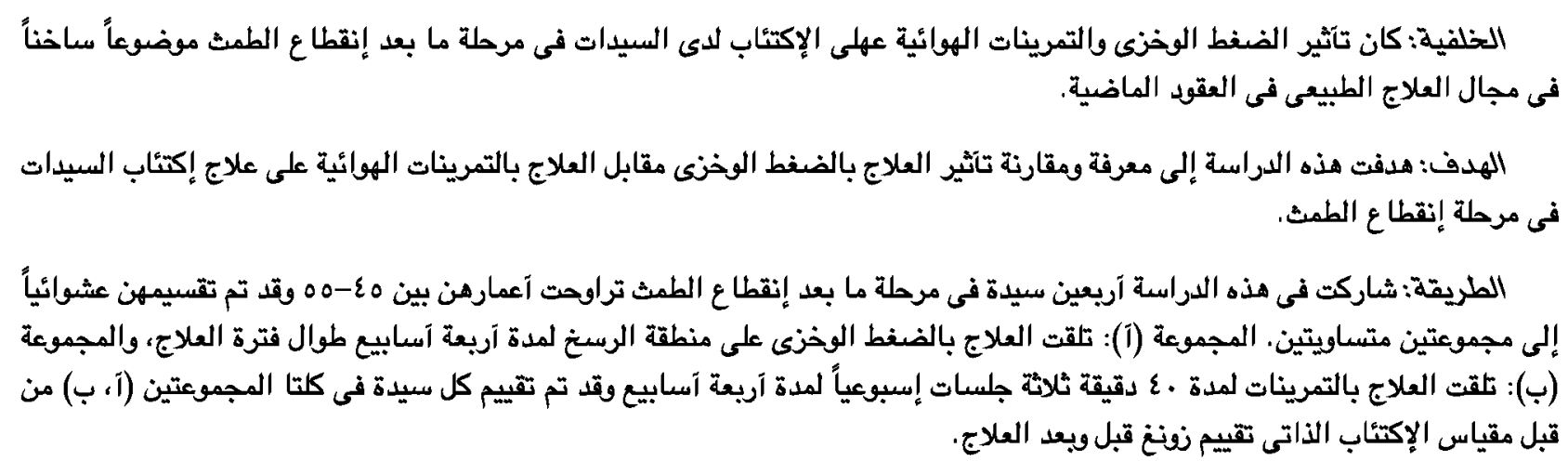

النتائج: آثبتت النتائج الإحصائية ما يلى: بعد آربعة آسابيع من العلاج سجلت كلا من المجموعتين إنخفاضاً ذودلالة إحصائية لمعدل

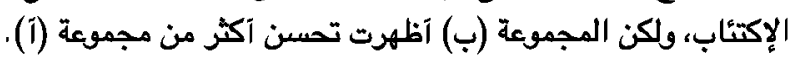

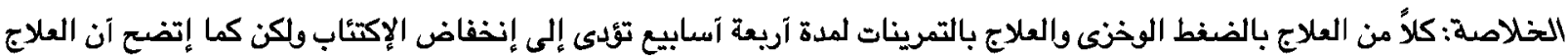
بالتمرينات له تآثير آكبر من تآتير العلاج بالضغط الفير الفخى على إنخفاض الإكتئاب لدى السيدات في مرحلة ما بعد إنقطاع الطمث. 